\title{
JEAN CLAIR: MALESTAR EN LA INCULTURA
}

\section{Eduardo Creus Visiers}

(Università degli Studi di Torino)

Jean Clair, La part de l'ange. Journal 2012-2015, Paris, Éditions

Gallimard, 2016, 416 pp. ISBN: 978-2-07-010686-8

La part de l'ange: un espacio que los niños dejaban en la almohada para el reposo del ángel de la guarda, el vapor de coñac que escapa durante el proceso de embotellamiento, también la porción de dolor humano que la presencia espiritual custodia, y hasta en algún momento el instante de la liberación del discurso en la terapia analítica. Pero La part de l'ange. Journal 2012 2015 es sobre todo el nuevo libro de Jean Clair: un entramado de ensayos —más que diario en el convencional sentido del término- nacidos al azar de las sensaciones cotidianas, que puede adscribirse a la fértil tradición literaria que arranca con Montaigne y llega sin mayores incidencias hasta hoy mismo. Compuesto al modo de los precedentes Court traité des sensations (2002), Dialogue avec les morts (2011) o Les derniers jours (2013), La part de l'ange es, en cierta manera, continuación y complemento de esos écrits intimes. Reencontramos en sus páginas reflexiones en torno a la fascinación de la palabra (la palabra justa, «pour ne pas perdre le fil, le fil de la vie»), la necesidad y la angustia de la escritura, la belleza como consolación o refugio, el recuerdo de la infancia en Pantin y el exilio de ese reino de humilde existencia provinciana, el pudor y el impudor del cuerpo, la sacralidad perdida, la omnipresencia del sueño, la desazón de la muerte... A modo de letanía obsesionante, las reflexiones de Clair vuelven una y otra vez sobre estos motivos y acaban por revelarnos cómo en la vorágine de los días ha ido atrapándonos la alucinación de un mundo virtual, de apariencias evanescentes, y cómo el abandono de todo valor no mercantil nos deja a merced de una modernidad que naufraga sin resistencia y sin remedio en lo insustancial. Al Jean Clair que denunciaba con tonos casi cioranianos un arte 
contemporáneo vaciado de esencia, agotado en su capacidad renovadora, ha ido sucediendo un Clair de la reflexión sobre la propia identidad en brega con el confuso presente. Matizados —no extinguidos - ciertos furores verbales de antaño, su escritura gana en gravidez, sin pérdida de la incisiva claridad de entonces. Hay, tal vez, mayor fatiga o mayor desesperanza; hay también, qué duda cabe, mayor ahondamiento.

A ningún lector de Clair sorprenderá el protagonismo del arte en estas páginas, dado que es materia sobre la que ha escrito innumerables libros, algunos tan fascinantes y polémicos como los dedicados a las vanguardias, a las cuales ha sometido a examen implacable —baste recordar La responsabilité de l'artiste (1997) o Du surréalisme considéré dans ses rapports au totalitarisme et aux tables tournantes (2003)—. Clair ha puesto en entredicho los vínculos entre esas corrientes y ciertos ideales de raigambre progresista o libertaria de la modernidad a los que fácilmente se asociaban, y ha insistido en sus tendencias irracionales y oscurantistas: culto a la violencia, iconoclasia, ocultismo, teosofía y obsesiones telúricas varias. La revolución presunta del arte moderno puede entenderse, vistas así las cosas, como decantación del pensamiento reaccionario o como mero instrumento, en el mejor de los casos, de una modernidad desmantelada. Las tesis de Clair al respecto, bien conocidas, están latentes en las páginas de La part de l'ange y emergen en ciertas alusiones, pero la atención no está ya puesta en la crítica de la abdicación del arte moderno, de la disgregación estética que oscuramente anuncia los desastres de un siglo de inaudita violencia o del desenmascaramiento de «l'utopie du Novum», sino en la fuerza intemporal de la belleza que acaso salve al mundo, si el mundo encuentra la fuerza necesaria para salvar la belleza.

Rescate al que poco ayuda el mercantilismo que hoy impera en el terreno del arte, con su soberana ignorancia de toda distinción entre los conceptos de valor y precio. Clair no muestra la menor indulgencia con ese ambiente que procede a la devaluación sistemática de cuanto tasa, trátese de las «reliques de la religion moderne» que son las obras maestras canónicas o bien de las más recientes, sometidas a especulaciones financieras que nada tienen que ver con sus posibles cualidades estéticas. A la vieja admiración por la belleza ha ido sustituyéndola el asombro ante las cifras descabelladas que ciertas obras alcanzan en la subasta pública, mientras el arte se ha convertido más que en valor de mercado, en su símbolo o su emblema. La pregunta sobre la esencia del arte queda hoy sin respuesta y en los museos se exhiben colecciones de 
objetos de los que hemos olvidado el origen y desconocemos su significado. ¿Qué hallan en esos lugares los ruidosos visitantes que los Ilenan en los días de ocio? Tal vez nada, pero el mundo actual, decía Clair en Malaise dans les musées (2007), funciona sin contenido. La pintura del pasado siglo se interpretó como manifestación de la vitalidad creativa que a menudo acompaña a los tiempos interesantes; se ha entendido también como síntoma de la decrepitud de nuestra cultura, grito de angustia y señal de disgregación venidera. $Y$ es posible ir todavía más atrás en el tiempo, porque en el vasto arco temporal de nuestra modernidad, las artes —y más las plásticas que la literatura o la música — han anunciado siempre, como órganos especialmente sensibles del cuerpo enfermo, el advenimiento de las crisis. ¿Pueden hacerlo aún? Ortega y Gasset observó que toda crisis es signo de vitalidad, que es su ausencia lo preocupante. Tal vez por ello el silencio del arte no puede ser buen presagio.

Lo anterior no es ejemplo del mejor optimismo, y lo que sigue tampoco va a serlo, porque el último libro de Clair es ante todo la declaración de un malestar que no cesa. Malestar en la insuficiencia de la cultura, en el empobrecimiento de la palabra, en el espejismo de una democratización de no menos ilusorios valores, y malestar también en los lugares: en la indefinición creciente del propio entorno geográfico, en la alienación de una vida urbana que es ya la única concebible mientras los últimos vestigios de la rural desaparecen velozmente, en el deterioro de un mundo de cuyos presuntos encantos son testimonio falaz la guía turística y el selfie, ese «triomphe terminal de l'idiot»... Entendemos entonces la importancia que otorga Clair a sus cari luoghi, a sus refugios, bibliotecas y escondidos Nautilus. Y, por lo mismo, lo que para el autor representan la escritura, con su flaubertiana exigencia de precisión en la palabra y el ritmo, y la lectura, ese esfuerzo incesante de «s'accorder avec la voix des morts» que nos trae a la mente el «y escucho con mis ojos a los muertos» de nuestro Quevedo, maestro de un secreto diálogo más necesario hoy que nunca.

La palabra, afirma Clair en La part de l'ange, nos acerca a lo real con mayor eficacia que la imagen: sugiere, no subyuga ni impone, pese a lo cual se ve hoy aquejada de una singular impotencia para decir las cosas, para representarlas en su transparencia. El ejercicio de la escritura —como la práctica psicoanalítica, «le dernier des humanismes»—- puede entonces revelar su sentido profundo en la superación de esa insuficiencia. Clair declara su renuncia deliberada a la construcción de mundos ficticios y opera en múltiples direcciones a partir de 
un proceso de introspección radical; el resultado, sin embargo, no se nos ofrece en secuencias de un mundo cerrado, sino como coherente tentativa de restituir a la palabra la capacidad de representar esa transparencia del mundo. Su modo es también un inquirir enérgico —recuérdese su alineamiento, a propósito del conflicto balcánico, con la valiente posición de Peter Handke, uno de los pocos escritores que aún nos quedan-, y esas inquisiciones pueden fácilmente confundirse con las actitudes reaccionarias que a menudo se le han reprochado sin mayor fundamento. Todos los textos de La part de l'ange y no solo los más personales, los que aparecen bajo el quizá engañoso título «Fragment d'un Journal», son momentos de un mismo discurso de la intimidad construido al hilo de muy tenues vínculos argumentales —una impresión, una imagen, un recuerdo, un malestar-, suficientes para desencadenar la escritura. El libro se nos revela entonces como exorcismo contra el amenazador silencio de la palabra, como afirmación obstinada de lo real frente a la irrealidad de la muerte.

Hacia el final de La part de l'ange afronta Clair la actual reviviscencia del poder de la imagen, en las penosas circunstancias que el terrorismo islámico ha propiciado, tras su lento apagamiento en el pasado siglo y su devaluación absoluta. Ya en los años ochenta observaba Jean Baudrillard que la modernidad, igual que el Barroco, es productora incesante de imágenes, con la diferencia de que su profusión es secretamente iconoclasta: incontinencia de la imagen sin consecuencias, en la que nada hay que ver. El último Malraux previó, sin embargo, un retorno al conflicto religioso que habría de serlo de la imagen y el símbolo, y es a nuestra somnolienta iconoclasia a la que toca ahora presenciar esa barbarie de cuyo signo no podemos siquiera estar seguros. La part du diable. Si es fácil aquí el desacuerdo con ciertos énfasis de Clair, una lectura atenta no será mal antídoto contra los hábitos de nuestra indiferencia. En cualquier caso no son estas amargas reflexiones las que cierran el libro. A modo de conclusión agrega Clair un muy breve capítulo o coda dedicado al conmovido recuerdo de un maestro de infancia. Esas últimas notas, las más delicadas de La part de l'ange, son acaso también las esenciales.

Al igual que otros escritos del autor, La part de l'ange se publica en la colección Blanche de Gallimard, cuyos elegantes volúmenes mantienen todavía la sobria estética de antaño, que la editorial suaviza a veces añadiéndoles una faja sin vacuos comentarios y con una bella foto en blanco y negro. Para el libro de Jean Clair se ha elegido una célebre: la de la estatua que representa la Alegoría de la Bondad del edificio del Ayuntamiento en Dresde, aún en pie tras los 
bombardeos de 1945. Desde donde está hecha la foto —una altura inverosímil—, la figura nos da la espalda y parece la de un ángel levemente inclinado sobre la devastación de la ciudad, en gesto de compasión infinita o desesperada impotencia. «Nous vivons — escribió una vez Valéry-comme nous pouvons dans le désordre de ces ruines, ruines elles-mêmes inachevées, ruines qui menacent ruine...» 